\title{
KUASA PEREMPUAN DALAM SEJARAH INDONESIA KUNA ${ }^{1}$
}

\author{
Ufi Saraswati \\ Jurusan Sejarah, Universitas Negeri Semarang
}

\begin{abstract}
Abstrak. Tulisan-tulisan tentang perempuan pada masa Jawa Kuna pada umumnya bersifat fragmentaris, sehingga dapat disampaikan bahwa sampai saat ini belum banyak dijumpai adanya tulisan yang mengaji perempuan secara mendalam dan komprehensif, khususnya yang membahas kuasa mereka dalam perannya sebagai perempuan. Kesetaraan kedudukan dan peranan perempuan dalam masyarakat Jawa Kuna hampir mencakup dalam pelbagai aspek kehidupan. Data tekstual maupun artefaktual di bidang politik, dapat diketahui bahwa perempuan dapat menduduki jabatan mulai dari jabatan pada struktur birokrasi yang paling rendah di pedesaan sampai kepada jabatan tertinggi. Meskipun dari segi kuantitas tidak sebanyak laki-laki, namun berdasarkan fakta yang tersampaikan dari kedua jenis data tersebut dapat disimpulkan bahwa laki-laki maupun perempuan pada masa Jawa Kuna mempunyai kesempatan yang sama untuk meraih jabatan publik. Kaum perempuan pada masa Jawa Kuna dalam bidang sosial sudah terlibat dalam kegiatan-kegiatan sosial, baik sebagai pendamping suami maupun sebagai diri sendiri. Data tekstual maupun artefaktual menggambarkan adanya istri-istri yang mendampingi suaminya berkaitan dengan kedudukan dan peranannya sebagai istri, terutama di kalangan bangsawan dimana kaum perempuan mempersiapkan dirinya untuk mendapatkan suami yang sesuai melalui pendidikan etika, seni, satra dan bahasa, seperti tercermin dalam teks-teks sastra pada masa Jawa Kuna.
\end{abstract}

Kata-kata kunci: kuasa perempuan, data tekstual \& konstektual, Indonesia kuna

\begin{abstract}
The works on woman in the ancient period are generally fragmentaric works. Therefore, there is no paper which could elaborate the women history in-depth and comprehensively, especially discussing their power in the role as the women. The egality of position and role in the ancient Javanese society is almost comprising all aspects of life. Based on textual and contextual data in political aspect, it could be known that women could reach the position started from the lowest bureaucracy in village to the highest position like a queen. However, the men are more than women in term of quantity but based on the facts, between men and women have the same opportunity to gain political position. Women in the ancient Javanese in social aspect have already engaged in the social activities. Between textual and contextual data describe that the women accompany their husbands related to the position and role as the wifes, mainly in the aristocratic class when the women preparing themselves to gain the proper husband through th ethical, art, literature, and language education; as reflected in the textual soucres in the ancient Javanese.
\end{abstract}

Keywords: the power of women, textual and contextual data, ancient Indonesia

Sejarah mencatat adanya peran wanita di bidang politik. Wanita Indonesia sudah berperan dalam bidang politik jauh sebelum kolonialisme Barat. Nama-nama yang patut dicatat diantaranya adalah Ratu Sima, Sanggramavijaya, Dharma Prasada Tunggadewi (tangan kanan Erlangga) dan sederet lainnya yang merupakan namanama yang sangat dikenal di seluruh Indonesia. Kesaksian tentang peranan wanita banyak dijumpai dalam periode awal kerajaan-kerajaan Jawa. Salah satunya terdapat dalam kisah Wangsa Isyana dan keturunannya mendirikan kerajaan Singasari dan kerajaan Majapahit. Ken Dedes seorang tokoh dalam kerajaan Singasari merupakan salah satu contoh bagaimana seorang wanita menjadi dalang bagi peralihan kekuasaan dari Tunggul Ametung ke Ken Arok.

Kesetaraan jender antara kaum perempuan dan kaum laki-laki dalam

\footnotetext{
${ }^{1}$ Artikel ini merupakan pengembangan dari makalah yang pernah disajikan dalam Seminar Nasional Perempuan dalam Arus Sejarah tanggal 21 April 2016 di Universitas Negeri Malang
} 
perspektif sejarah sesungguhnya bukan hal baru. Perempuan Indonesia pada masa Mataram Kuna sampai masa Majapahit sudah memperoleh kedudukan dan peranan setara dengan laki-laki dalam berbagai aspek kehidupan. Pada masa Jawa Kuna, Titi Surti Nastiti dalam disertasinya yang berjudul "Kedudukan dan Peran Perempuan dalam Masyarakat Jawa Kuna Abad 8-15 Masehi" menyampaikan bahwa pada masa Jawa Kuna kaum perempuan dan laki-laki mempunyai kesempatan sama walaupun dari segi kuantitas tidak sebanyak kaum laki-laki. Menurut Nastiti selanjutnya dinyatakan bahwa kesetaraan dapat dicapai dalam meraih jabatan publik, kegiatan sosial, ekonomi, dunia kesenian, dan lainnya.

Di bidang pemerintahan, istri bisa mempunyai kekuasaan lebih tinggi daripada suaminya. Contohnya, Wikramawarddhana ketika mengeluarkan prasasti Patapan II (1385 M) dan prasasti Tirah atau Karang Bogem (1387 M) yang menggunakan lambang daerah Lasem, daerah kekuasaan Kusumawarddhani, istrinya. Pada saat itu, Wikramawarddhana belum menjadi raja. Penggunaan lambang tersebut mencerminkan kekuasaan Kusumawarddhani lebih besar daripada Wikramawarddhana. Hal sama terjadi pada Bhre Wirabhumi yang mendapat gelar dari istrinya, Nagarawarddhani. Bhre Wirabhumi sebelum menjabat sebagai penguasa Lasem, Nagarawarddhani menjabat penguasa daerah Wirabhumi.

Nastiti melakukan kajian
berdasarkan data tekstual dan artefaktual. Data tekstual berupa prasasti dari masa Mataram Kuna sampai masa Majapahit dalam bentuk teks sastra dan kumpulan teks, tertua seperti Ramayana dari masa Rakai Watukura Dyah Balitung sampai teks sastra dan hukum dari masa Majapahit. Data artefaktual yang sezaman diantaranya menggunakan arca, dan relief yang menempel pada candi atau stupa.

Kesetaraan kedudukan dan peranan antara perempuan dan laki laki sejak masa Mataram Kuna sampai masa Majapahit berakar pada budaya yang tidak membedakan hak waris di semua kalangan. Tidak adanya perbedaan hak waris tersebut mempengaruhi konsep domestik dan publik sehingga laki-laki maupun perempuan dapat menjabat jabatan publik asalkan mengikuti ketentuan. Ada aturan tertentu yang harus diikuti dalam hal ini, misalnya untuk menduduki posisi putra atau putri mahkota harus anak pertama dari permaisuri, contohnya Sri Rajasawarddhani yang dalam prasasti Kancana atau yang disebut prasasti Bunur $B$ menyebutkan, ia anak bungsu Hayam Wuruk. Dari kakawin Nagarakrtagama diketahui yang disebut sebagai Kusumawarddhani adalah putri mahkota. Putra pertama Hayam Wuruk seperti disebutkan teks Pararaton adalah Bhre Wirabhumi, karena bukan putra dari permaisuri, ia tidak dapat menjadi putra mahkota

\section{WANITA DALAM PANDANGAN MASYARAKAT JAWA}

Wanita Jawa sangat identik dengan kultur Jawa, seperti bertutur kata halus, tenang, diam (kalem), tidak suka konflik, mementingkan harmoni, menjunjung tinggi nilai keluarga, mampu mengerti dan memahami orang lain, sopan, pengendalian diri tinggi atau terkontrol, dan daya tahan untuk menderita tinggi. Bila ada perselisihan ia lebih baik mengalah, tidak gegabah, tidak grusa-grusu, dan dalam mengambil langkah mencari penyelesaian dengan cara halus. Dalam konsep budaya Jawa terdapat beberapa istilah tentang wanita, yaitu : wadon, pawèstri, putri, wanodya, retna, kusuma, memanis, juwita, 
wanita, dan dayita, masing-masing istilah ini mempunyai arti tersendiri yang menunjukkan bahwa wanita dalam pandangan masyarakat Jawa memiliki peran istimewa (Basuki, 2005:5).

Kata wanita dalam etimologi Jawa itu berasal dari wani ditoto alias berani diatur. Menurut Old Javanese-English Dictionary (Zoetmulder, 1982), kata wanita berarti ‘yang diinginkan'. Dari sudut pandang feminis, tentu saja pe-labelan 'wanita' ini adalah jejak-jejak peninggalan kultur Patriarki yang tertinggal dalam tatanan bahasa Indonesia. Wanita jadi diukur lewat seberapa besar tingkat kesetiaannya kepada lawan jenisnya, walaupun ternyata dalam Kamus Besar Bahasa Indonesia (KBBI) pun berpihak kepada wanita sebagai ameliorasi dari perempuan:

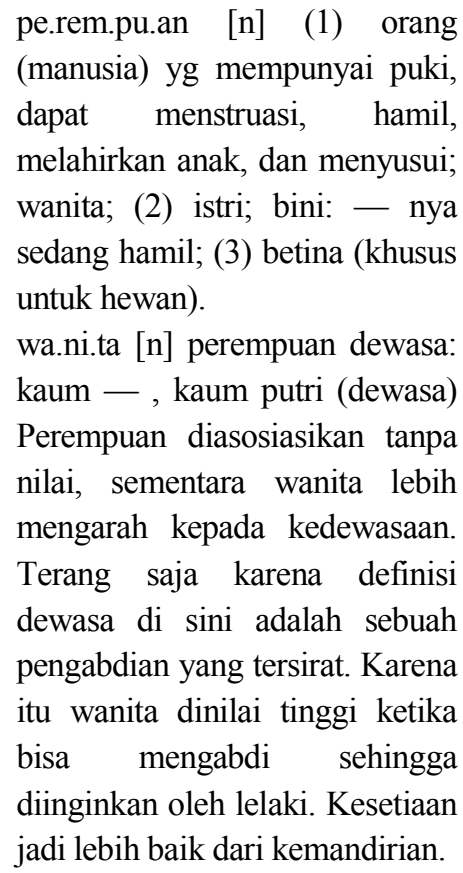

Ternyata nilai wanita yang lebih tinggi dalam bahasa Indonesia ini menurut Ben Anderson (1966) adalah karena bahasa Indonesia mengalami "jawanisasi" atau "kramanisasi", kulitnya saja bahasa Melayu yang egaliter, tapi rohnya bahasa Jawa yang feodal. Arti kata perempuan sementara itu dari bahasa asalnya yaitu bahasa Sansekerta sangat berbeda dengan apa yang ada di KBBI. Perempuan berasal dari kata per-empu-an. Per itu berarti makhluk, Етрu berasal dari kata Sansekerta yang berarti mulia, berilmu tinggi, pembuat suatu karya agung. Leluhur bangsa ini pun sudah memberikan makna dalam kata perempuan sebagai bentuk penghormatan tinggi kepada kaum wanita.

Masyarakat Indonesia dikenal dengan sistemnya yang Patriarkis meskipun sebenarnya terdapat variasi corak Patriarki antar budaya. Salah satu masyarakat yang dikenal dengan kebudayaannya yang Patriarkis adalah Jawa. Dalam budaya Jawa yang cenderung paternalistik laki-laki memiliki kedudukan yang istimewa (Handayani dan Novianto, 2004: 65).

Istilah wanita itu sendiri berasal dari bahasa Jawa yang berarti wani ditata (berani ditata). Pengertian ini telah mencirikan adanya tuntutan kepasifan pada perempuan Jawa. Selain itu istilah putra mahkota (bukan putri mahkota), kawin paksa, dan babakan pingitan yang diberlakukan kepada perempuan yang akan menikah, menurut Widyastuti sebagai persoalan gender yang dihadapi perempuan Jawa. (Widyastuti, 2007: 67).

Mulai dari awal pemilihan pasangan hidup, laki-laki Jawa biasanya disarankan untuk tidak memilih perempuan yang memiliki status sosial dan ekonomi yang lebih tinggi. Selanjutnya dalam perkawinan, istilah kanca wingking, yakni bahwa perempuan adalah teman di dapur akan mewarnai kehidupan perkawinan pasutri Jawa. Istilah konco wingking pun tidak selalu lebih rendah, tergantung bagaimana perempuan Jawa memaknainya.

Jika perempuan selalu diidentikkan sebagai kanca wingking (teman di dapur) yang sering ditafsirkan oleh masyarakat 
Jawa pada umumnya sebagai kepasifan perempuan dan tugasnya hanya pada urusan rumah tangga, tidak demikian halnya dengan uraian dari berita Cina abad 7-8 M tentang keberadaan Ratu Sima dari Kerajaan Kalingga (Keling) sebagai raja wanita pertama yang memerintah pada abad 6-7 M di Jawa. Berita Cina dari Dinasti Tang mengatakan bahwa kerajaan Holing (Kalingga) di Pulau Jawa ini sangat kuat. Orang Ta-Shih pada tahun $674 \mathrm{M}$ mengurungkan niatnya untuk menyerang Negara ini disebabkan oleh keperkasaan Kalingga. Diberitakan pula bahwa di bawah pemerintahan Ratu Sima, Kerajaan Kalingga menjadi pemerintahan negara yang sangat menjunjung tinggi hukum, bahkan, pernah saudara ratu sendiri terpaksa harus dihukum karena berani melanggar peraturan.

Kepemimpinan Ratu Sima ini menunjukkan bahwa kepemimpinan sebuah negara dalam pengambilan keputusan sekalipun di bawah kendali seorang perempuan tidak berarti akan mendorong pada kemunduran dan kegagalan. Dengan demikian, dapat dikatakan bahwa dengan tidak adanya protes atas kepemimpinan Ratu Sima tersebut juga menunjukkan bahwa masyarakat jawa kala itu sebenarnya sudah memberikan ruang yang besar pada perempuan untuk tidak hanya bergelut dengan urusan rumah tangga tapi juga dapat turut campur dalam urursan kenegaraan.

Adanya konsep istri sebagai sigaraning nyawa, bukan sekedar konco wingking juga memberikan gambaran posisi yang sejajar dan lebih egaliter terhadap perempuan Jawa. Selain itu Handayani \& Novianto juga berpendapat bahwa perempuan Jawa bukannya tidak memiliki otoritas pribadi. Hanya saja ia harus mencari cara agar kehendaknya terpenuhi tanpa mengacaukan harmoni dengan keluar dari tatanan budaya.

\section{KUASA PEREMPUAN DALAM SEJARAH INDONESIA KUNA}

Masa sejarah di Indonesia dibagi lagi atas sejarah kuna dan sejarah modern. Sejarah kuna ialah masa sejarah yang dimulai sejak adanya pengaruh India yang berupa tulisan sampai masa kolonial, sedangkan sejarah modern mengacu pada masa kolonial yang ditandai dengan datangnya bangsa Eropa ke Nusantara sampai sekarang. Sepanjang sejarah kebudayaan Indonesia, terdapat tiga gelombang kebudayaan besar yang datang ke Indonesia yaitu kebudayaan India, kebudayaan Islam, dan kebudayaan Eropa. Kedatangan ketiga kebudayaan tersebut menyebabkan terjadinya Akulturasi antara kebudayaan Indonesia dengan ketiga kebudayaan itu.

Dalam kajian ini yang berjudul Kuasa Perempuan dalam Sejarah Indonesia Kuna. maka yang menjadi topik pembahasannya adalah segala kegiatan perempuan yang didapatkan dari data tekstual maupun data artefaktual dengan memakai kategori analisis gender yang berlaku pada masa Sejarah Indonesia Kuna. Gender adalah prinsip dasar dari hubungan sosial manusia yang didasarkan pada perbedaan dan persamaan laki-laki dan perempuan yang dibentuk secara kultural (Conkey dan Gero 1994:8; Preucel dan Hodder 1996:418; Gilrischt 1997:8; Hays-Gilpin dan Whitley, 1998:xv).

Rentangan masa dalam kajian yang cukup panjang (kurang lebih 7 abad) yaitu mulai dari masa Matarām Kuna sampai akhir Majapahit karena data tekstual (prasasti, teks sastra/hukum, berita asing) yang menuliskan mengenai perempuan sangat sedikit dan fragmentaris, sehingga apabila hanya mengkaji dalam satu masa 
saja sangat sulit untuk mendapat gambaran mengenai kedudukan dan peranan perempuan pada masa Jawa Kuna yang utuh.

\section{Bukti Tekstual}

Dalam data prasasti, baik laki-laki maupun perempuan banyak menduduki jabatan pemerintahan sebagaimana dijumpai pada prasasti Juruüan (876 M) dan prasasti Wariüin Pitu (1477 M). Perempuan pada masa itu juga sudah melibatkan diri dalam kegiatan sosial sebagai pendamping suami maupun sebagai diri sendiri. Dalam prasasti Wulig (935 M), Rakai Mangibil, selir Mpu Sindok, meresmikan tiga bendungan. Sedangkan pada relief candi sering ditampilkan raja atau bangsawan ditemani perempuan.

Perempuan bukan sebagai alat hiburan semata, tetapi juga menjadi sumber penghasilan keluarga dan ada perempuan profesional dalam bidang seni pertunjukan. Namun, walaupun kaum perempuan pada masa itu sudah menikmati kesetaraan hampir di semua aspek kehidupan, dalam hal tertentu, terutama di bidang keagamaan, perannya masih lebih rendah dari kaum laki-laki dalam bela dan sati tukon. Perempuan tidak dapat menjabat sebagai pejabat tertinggi keagamaan atau menjadi Kawi.

Selain prasasti, teks-teks sastra pun banyak menuliskan kegiatan yang dilakukan oleh laki-laki dan perempuan terutama dari kalangan bangsawan. Dalam Teks sastra digambarkan bagaimana kaum perempuan menghabiskan waktunya untuk menulis puisi atau kegiatan lainnya, dan bagaimana gambaran laki-laki yang berangkat ke medan perang, dan sebagainya.

Kedudukan dan peranan perempuan pada masa Jawa Kuna dalam bidang ekonomi tidak perlu diragukan lagi, terutama perempuan dari kalangan rakyat biasa. Mereka membantu perekonomian keluarga dengan membantu suami menggarap sawah atau ladang. Di sela-sela kesibukan bekerja di sawah/ladang, menyelesaikan tugas-tugas rumah tangga, mereka membuat barang-barang kerajinan seperti kain, barang-barang anyaman, barang-barang dari tanah liat, gula, minyak, dan sebagainya, yang digunakan untuk keperluan sendiri dan dijual. Selain itu, kaum perempuan pun handal dalam berniaga, yang dibuktikan dengan adanya pedagang-pedagang di tingkat eceran sampai saudagar (bańigram $\vec{\imath}$ yang melakukan perdagangan tidak hanya di tingkat desa tapi mungkin sampai tingkat regional dan internasional.

Pada masa Jawa Kuna, masalahmasalah hukum diselesaikan oleh pejabatpejabat kehakiman. Tidak banyak data tekstual yang menuliskan tentang masalah hukum. Satu-satunya prasasti yang isinya berkaitan dengan perempuan yang mempunyai kaitan dengan hukum adalah prasasti Guntur (907 M.). Prasasti ini menyebutkan adanya perempuan yang menjadi saksi (tatra sākśî) dan pemutus suatu perkara (pinariccheda guńadośa).

Pada masa Majapahit selain pejabat kehakiman yang disebut i)t)dharmmopapat, ada semacam Dewan Pertimbangan Kerajaan (āra saptaprabhu) yang beranggotakan keluarga kerajaan. Pada masa pemerintahan Hayam Wuruk memerintah, yang menjabat sebagai Dewan Pertimbangan Kerajaan adalah raja, permaisuri, ayah-bunda raja paman raja, dua adik perempuan raja beserta suaminya. Apabila anggota Dewan Pertimbangan Kerajaan ini terdiri dari laki-laki dan perempuan, maka pejabat kehakiman di tingkat pusat tidak pernah dijabat oleh perempuan.

Meskipun tidak pernah disebutkan adanya pejabat keagamaan perempuan, tidak berarti bahwa kaum perempuan tidak 
mempunyai peranan dalam bidang agama. Dalam beberapa prasasti disebutkan adanya pasangan suami istri yang membebaskan atau membeli tanah untuk keperluan suatu bangunan suci sebagai dharmma mereka. Selain itu prasasti Taji (901 M.) menyebutkan adanya warga desa laki-laki dan perempuan yang membeli tanah bagi sima suatu bangunan suci.

Teks Mānawadharmaśāstra, Agastyaparwa, dan Kŕśńayana menuliskan bahwa perkawinan yang baik adalah perkawinan di antara orang yang sederajat. Pada masa Jawa Kuna, terutama masa Majapahit banyak perkawinan yang dilakukan di antara saudara sepupu

\section{Bukti Artefaktual}

Data artefaktual, terutama dijumpai pada relief-relief candi, baik candi-candi di Jawa Tengah maupun di Jawa Timur. Banyak adegan yang menggambarkan kegiatan laki-laki maupun perempuan baik di lingkungan kerajaan maupun di lingkungan masyarakat biasa. Kegiatan di lingkungan istana biasanya digambarkan dalam adegan-adegan paseban, sedangkan kegiatan di lingkungan masyarakat pada umumnya menggambarkan kehidupan sehari-hari, seperti bertani dan berladang sebagaimana yang terdapat di beberapa relief di Stupa Borobudur.

Di samping itu ada beberapa relief yang menggambarkan laki-laki dan perempuan yang sedang melakukan upacara keagamaan atau ada juga yang menggambarkan mereka sedang menari atau memainkan musik. Pada relief-relief candi banyak adegan yang memahatkan adegan-adegan orang yang sedang memuja candi, baik perseorangan, pasangan suami istri maupun kelompok. Satu di antaranya dipahatkan di Stupa Borobudur yang menggambarkan pasangan suami-istri dari kalangan bangsawan yang memuja stūpa.

Di dalam dunia seni, terutama seni pertunjukan, kaum perempuan pada masa
Jawa Kuna telah mempertunjukkan keahliannya di depan penonton. Dari data artefaktual diketahui bahwa keahliannya ini tidak hanya dipertunjukkan di dalam ruangan seperti yang dilakukan dalam pesta-pesta yang dilakukan oleh kaum bangsawan, tetapi juga ada kesenian yang dipertunjukkan di jalan. Bentuk-bentuk pertunjukan yang dipertontonkan selain tari-tarian juga sulap seperti yang digambarkan dalam relief Stupa Borobudur. Bagi perempuan pada Jawa Kuna, seni bukan hanya sebagai alat hiburan saja akan tetapi juga sebagai sumber penghasilan. Pada masa itu telah ada kaum perempuan profesional dalam bidang seni pertunjukan.

\section{PENUTUP}

Menarik untuk diungkapkan adalah adanya perbedaaan gambaran mengenai kedudukan dan peranan perempuan dalam masyarakat Jawa Kuna antara apa yang ditulis dalam prasasti dan teks-teks sastra terutama kakawin. Data prasasti menunjukkan bahwa perempuan telah memegang peranan penting dalam masyarakat (van Setten van der Meer, 1979; Ayatrohaédi, 1986; Lombard, 1990; Nastiti 1998, 2001). Sebaliknya dengan kakawin yang menggambarkan perempuan masa lalu stereotip sebagai orang yang lemah dan subordinat dari laki-laki. Apabila diamati adanya perbedaan perspektif itu dikarenakan sumber-sumber yang dipakai berbeda.

Beberapa Sarjana dan sumber Prasasti yang menuliskan bahwa kedudukan dan peranan perempuan setara dengan laki-laki didasarkan pada cerita rakyat asli dari Indonesia dan peristiwa yang pernah terjadi di Jawa. Helen Creese (2001), sementara sarjana yang menuliskan bahwa perempuan adalah subordinat lakilaki didasarkan pada uraian kakawin yang 
ceritanya berasal dari India dimana budayanya sangat androsentris. Maka dengan demikian jelas bahwa meskipun prasasti maupun kakawin sama-sama ditulis di Jawa, akan tetapi karena latar belakang budaya yang berbeda maka penggambaran mengenai kedudukan dan peranan perempuan pun berbeda.

Dalam pembagian pekerjaan berdasarkan jenis kelamin yang didasarkan pada maskulinitas dan feminitas seseorang sesuai dengan jenis kelaminnya, dapat diamati dalam kehidupan sehari-hari mayarakat Jawa Kuna. Pertama adalah pekerjaan-pekerjaan yang membedakan pekerjaan antara laki-laki dan perempuan, terutama pekerjaan yang menyangkut fisik dan umumnya terdapat di dalam masyarakat kalangan bawah. Kedua, pekerjaan-pekerjaan yang tidak membedakan laki-laki atau perempuan, terutama berlaku pada pekerjaan-pekerjaan yang tidak memakai kekuatan fisik. Jenis pekerjaan seperti itu didapatkan di setiap lapisan masyarakat, seperti jabatan-jabatan yang ada di desa maupun di pusat.

Pembagian kerja secara fisik dapat diamati dari data artefaktual yang berupa relief misalnya, digambarkan perempuan menanam padi dan memanen hasil pertanian, sedang laki-laki mencangkul dan membajak. Selain itu ada pekerjaanpekerjaan lain yang tampaknya dibedakan atas fisik mereka seperti yang tergambar dalam relief-relief. Digambarkan dalam relief beberapa pekerjaan laki-laki misalnya, keluar rumah untuk menangkap ikan, berburu, menggembala, dan sebagainya sementara perempuan mengerjakan pekerjaan rumah tangga seperti mengasuh anak, memasak, serta membuat produksi rumah tangga seperti menenun dan membuat barang-barang dari tanah liat. Tetapi tidak berarti bahwa lakilaki tidak bisa memasak, karena ada beberapa relief yang menggambarkan laki- laki yang sedang memasak dalam kesempatan-kesempatan tertentu. Pekerjaan-pekerjaan seperti telah disebutkan di atas masih dapat ditemukan di dalam kehidupan masyarakat Jawa dan Bali sekarang, meskipun ada beberapa pekerjaan yang sudah mulai berangsurangsur hilang bahkan ada yang sudah lenyap sama sekali. Adanya pembagian pekerjaan tersebut bukan berarti kelompok yang satu mendominasi yang lain, akan tetapi justru saling melengkapi karena mereka sadar akan adanya perbedaan fisik antara laki-laki dan perempuan.

Tidak semua peranan dan kedudukan perempuan dalam kehidupan masyarakat Jawa Kuna setara dengan lakilaki. Ada beberapa aspek yang tidak setara, baik ketidaksetaraan itu lebih tinggi atau lebih rendah dari laki-laki. Dapat dikemukakan di sini bahwa dalam percaturan politik, perempuan tidak saja dapat tampil di ranah publik karena ia memegang suatu jabatan, tetapi juga berperan secara tidak langsung di belakang suaminya. Berdasarkan data tekstual dapat diketahui ada beberapa raja yang diduga menjadi raja karena perkawinan. Sebagai contoh adalah Rakai Watukura Dyah Balitung yang diasumsikan menikah dengan putri mahkota. Seperti diketahui bahwa ayah Balitung hanyalah seorang raja bawahan (haji). Demikian pula dengan Airlangga dan Raden Wijaya, keduanya menikahi putri mahkota dan putri-putri raja pendahulunya.

Adapun peranan perempuan yang lebih rendah dari laki-laki adalah bela atau sati, tukon, perempuan yang tidak dapat menjabat sebagai pejabat-pejabat tertinggi keagamaan atau perempuan tidak dapat menjadi seorang Kawi. Apabila ditelusuri asal mula dari adat istiadat yang menyebabkan adanya ketidaksetaraan maka dapat diketahui bahwa semua itu berasal dari kebudayaan India. Meskipun 
demikian dalam mengadopsi kebudayaan India, masyarakat Jawa Kuna tidak menerapkan langsung ke dalam budayanya, tetapi ada hal-hal yang disesuaikan dengan budayanya. Seperti yang disebutkan oleh berita Portugis yang melakukan bela atau sati ini tidak hanya dilakukan oleh perempuan tetapi juga oleh laki-laki bangsawan yang bunuh diri sebagai tanda setia kepada rajanya. Adanya laki-laki yang ikut bela atau sati tidak didapatkan di negara asalnya. Selain itu dalam melakukan bela atau sati, perempuan tidak langsung menerjunkan diri langsung ke dalam api yang berkobar seperti yang terjadi di India, tetapi menikam dirinya dulu sebelum jatuh ke dalam api. Hal ini mungkin dilakukan untuk mengurangi rasa sakit dari perempuan yang melakukan bela atau sati dan lebih manusiawi daripada yang dilakukan di India.

Dalam masalah hukum pun, hukuman yang dijatuhkan kepada laki-laki yang melakukan pelecehan seksual (paradāra) lebih berat daripada aturanaturan yang terdapat dalam perundangundangan di India, meskipun seperti telah dikemukakan bahwa kitab-kitab perundangan-undangan yang ada di Jawa bersumber kepada kitab-kitab perundangundangan India. Perbedaan ini karena seperti yang disebutkan dalam prasasti Bendosari dan Paruy adalah karena masyarakat Jawa Kuna telah mempunyai hukum adat yang dijadikan dasar pertimbangan selain kitab-kitab hukum.

Adanya anugerah raja kepada pejabat yang telah berjasa seperti angjamah rare, angjamah kawula, dan menikahi ůayang, meskipun hal ini tampaknya merendahkan derajat kaum perempuan, tetapi apabila diteliti secara seksama sebenarnya hal ini merupakan bentuk perlindungan terhadap perempuan, karena dengan adanya hak-hak istimewa sebagai anugerah raja, maka tidak sembarang laki-laki terutama dari kalangan bangsawan yang dapat melakukan hal-hal yang melecehkan kaum perempuan tersebut.

\section{DAFTAR PUSTAKA}

Ayatrohaédi, ed. 1986. Kepribadian Budaya Bangsa. Jakarta: Pustaka Jaya.

Basuki, A. R. 2005. Perempuan (di mata Budaya Jawa). Bende Media Informasi Seni dan Budaya. Surabaya: Dinas Pendidikan dan Kebudayaan Jawa Timur.

Conkey, M.W. dan J. M. Gero. 1994 "Tensions, Pluralities, and Engendering Archaeology: An Introduction to Women and Prehistory". Dalam Joan M. Gero and Margaret W. Conkey, ed. Engendeing Archaeology. Women and Prehistory. Oxford UK \& Cambridge USA: Blackwell, page :3-30. Cetak ulang.

Creese, H. 2001"Images of Women and Embodiment in Kakawin Literature", dalam Intersections: Gender, History and Culture in the Asian Context, Issue 5, May 2001,

URL:http:/wwwsshe.murdoc h.edu.au/intersection/issue 5/creese. html, accessed 22 May 2001.

Gilchrist, R. Gender and Material Culture. The Archaeology of Religious Women. London dan New York: Routledge, 1997.

Handayani, C.S \& Novianto, A. 2004. Kuasa Wanita Jawa. 
Yogyakarta: LkiS Pelangi Aksara

Hays-Gilpin, K dan David S. Whitley. 1998. Reader in Gender Archaeology. London: Routledge, 1998.

Lombard, D. 1990. Nusa Jawa: Silang Budaya. Penelitian Sejarah Terpadu Bagian 3: Warisan Kerajaan-Kerajaan

Konsentris. Jakarta: Gramedia, 1996. Trans. dari Le Carrefour Javanais. Essai d"histore globale. III: L'heritage des royaumes concentriques.

Nastiti, T. S. 1998 "Wanita pada Masa Jawa Abad IX-XV Masehi”. Dalam Kongres Nasional Sejarah 1996. Subtema Pemikiran dan Analisis Teks Sejarah. Jakarta: Departemen Pendidikan dan Kebudayaan RI,hal:107-26.

2009. Kedudukan dan Peranan Perempuan dalam Masyarakat Jawa Kuna (Abad VIII - XV Masehi): Ringkasan Disertasi. Jakarta: Universitas Indonesia

Preucel, R. dan Hodder, I. 1996. Contemporary Archaeology in Theory, ed. Oxford; Cambridge, Massachusetts: Blackwell Publisher Ltd.

van Setten van der Meer, 1979.N.C. Sawah Cultivation in Ancient Java: Aspect of Development on the Indo-Javanese Period. Canberra: Australian National University Press.

Widyastuti, S.H. 2007 "Perempuan Menerjang Hambatan Budaya: Catatan Dari Lapangan" dalam Jurnal
Reformasi Ekonomi Vol. 8, No. 1. Januari-Desember 2007. 